\title{
A VIRADA CULTURAL E A CRISE DOS ESTUDOS LITERÁRIOS
}

\section{José Wanderson Lima Torres ${ }^{1}$}

Resumo: Analisa-se a centralidade do conceito de cultura na sociedade pósmoderna e suas conseqüências para os estudos literários. Aponta-se o conflito entre estudos culturais e estudos literários e vindica-se um lócus singular à teoria literária, partindo da hipótese de que a categoria do estético é antes um espaço ambíguo capaz de suscitar contestações aos discursos hegemônicos do que uma manifestação do elitismo cultural.

Palavras-Chave: Cultura, Estudos culturais, Estudos literários, Interpretação, Estética.

Resumen: Es un análisis de la centralidad del concepto de cultura en la sociedad postmoderna y sus consecuencias para los estudios literarios. Señala el conflicto entre estudios culturales y estudios literarios y vindica un lugar particular hacia la teoría literaria, basada en la hipótesis de que la categoría de lo estético es más bien un espacio ambiguo capaz de oponerse a del discurso hegemónicos que una manifestación de elitismo cultural

Palabras Clave: Cultura, Estudios culturales, Estudios literarios, Interpretación, Estética.

\section{INTRODUÇÃO}

O culturalismo, entendido aqui como a tendência a explicar as questões sociais a partir da noção de cultura, constitui uma transformação radical na abordagem das questões literárias. Fredric Jameson $(2001,2006)$ aponta que vivemos uma verdadeira "virada cultural" (cultural turn é sua expressão), enfatizando que na pós-modernidade a cultura foi economicizada e a economia foi culturalizada, de modo que economia e cultura são termos impensáveis separadamente.

Na modernidade, observa Jameson (2006), lutou-se bravamente contra a mercantilização da cultura; a realidade pós-moderna, porém, é inelutável: a cultura tornou-se mercadoria. Isto não significa que ela desapareceu; pelo contrário, ela se dilatou a tal ponto que nossa vida social tornou-se cultural. Assim, pensar o contexto pós-moderno é impossível sem se pensar as formas de produção e recepção da cultura.

Dentro dessa virada culturalista, ocupam especial lugar os estudos culturais da escola de Birmingham, que contribuíram para consideração da cultura como lugar essencial para se pensar as transformações históricas. Partindo de uma metodologia interdisciplinar e munidos de um forte senso de correção

1 Mestre em Letras pela Universidade Federal do Piaí - UFPI; Doutorando em Literatura Comparada pela Universidade Federal do Rio Grande do Norte - UFRN. Endereço eletrônico: wandersontorres@hotmail.com. 
política, os culturalistas de Birmingham passaram a textualizar as práticas culturais e tornaram o texto literário apenas uma das práticas culturais, desconsiderando as supostas especificidades dos textos artísticos.

Este estudo indaga se a prática culturalista, fundada num empenho ético que toma por elitista a questão estética, não acabou por dissolver a teoria literária. 0 objetivo final é sondar se ainda faz sentido, em pleno a virada cultural, os estudos literários². Teriam eles ainda lugar? Existiriam questões estritamente literárias que não estariam ao alcance da teoria cultural?

\section{UMA RUPTURA COM O PARADIGMa INTERPRETATIVO}

0 postulado, classicamente vinculado a Kant, segundo o qual à arte e à literatura devem ser atribuídas um tipo especial e intrínseco de valor, irredutíveis a valores de outros campos do saber, foi, grosso modo, a nota dominante da crítica literária, do formalismo russo ao estruturalismo, continuando a reverberar para além deste. Estudar a literatura, nas cercanias desta postulação, significou uma busca pela significação imanente do texto, uma perquirição dos procedimentos de produção do sentido.

Steven Connor (1994), em Teoria e valor cultural, denominou esta tendência nos estudos literários de "paradigma interpretativo". É o paradigma interpretativo o ponto de unidade e identidade institucional de teorias tão distintas entre si como o formalismo russo, new criticism, a estilística, o estruturalismo e a semiótica, pois em todas estas teorizações entrevê-se "um afastamento decisivo de uma preocupação com 0 julgamento e sua substituição pela preocupação com o significado e a interpretação" (1994, p. 20). Connor é perigosamente generalista e faz incluir no paradigma interpretativo até mesmo os estudos literários baseados no marxismo, no feminismo, na psicanálise e no pós-estruturalismo; para ele, é sempre o mesmo foco "nas atividades do conhecimento, da compreensão, da decodificação e da interpretação" (1994, p. 23).

0 fato, porém, de não se indagar nestas teorizações acerca da questão do valor não as exime de circunscrever-se a esta problemática. 0 desprezo da valorização não é o mesmo que neutralidade apática ou insensibilidade quanto às questões éticas. Está claro para Connor que o rechaço da valoração "é em si não uma recusa à valoração, mas uma forte e influente ação valorativa" (1994, p. 25), que tanto pode ser reacionária (new criticism) quanto progressista (pósestruturalismo, marxismo, feminismo).

2 Uso o termo genérico "estudos literários" para referir-me tanto à teoria quanto à crítica literária. 
Assim, a tese de Connor não é tanto a de que o paradigma interpretativo - ele se refere a este paradigma tal como pensado de 1970 até nós - tenha exilado os valores, mas que estes "foram jogados no inconsciente crítico, onde continuam a exercer pressão, se bem que sem estar disponíveis ao escrutínio analítico" (1994, p. 23). Percebe-se o quanto Connor tem razão quando em contato com obras como a de Foucault, Derrida, Kristeva, Edward Said e Jameson vislumbramos um empenho crítico e ético que se manifesta de forma evidente, mas distanciado da linguagem da moral e da retórica maniqueísta que põe em cena um mundo dividido entre os bons e os maus.

0 apoio de Connor serve-nos para dar azo à questão-problema a que pretendemos nos debruçar: não estaria a valoração, nas mãos dos praticantes dos estudos culturais, engendrado um novo paradigma, um paradigma axiológico, em contraposição ao paradigma interpretativo? Esta formulação se desdobra em outra ainda mais inquietante: não seria o paradigma interpretativo 0 agente justificador da existência dos estudos literários, que estariam em vias de dissolução uma vez que o paradigma axiológico, avesso aos valores estéticos, exige não uma crítica literária mas uma crítica cultural?

\section{A "Virada Cultural"}

Cultura, hoje, é um conceito-chave para se pensar o embate político que tomou conta da discussão sobre literatura. Os estudos culturais baniram do debate acadêmico a acepção elitista do termo; aposentaram a influente concepção de Mattew Arnold, que entende cultura como conjunto das "grandes obras", mormente textos, capazes de nos elevar o espírito. Stuart Hall (2003), um dos próceres da Escola de Birmingham, põe em pauta uma concepção de cultura sem a qual as transformações históricas não podem ser bem compreendidas. Os estudos culturais, atesta Hall, constituem uma oposição "ao papel apenas residual e de mero reflexo atribuído ao 'cultural'" (2003, p. 133).

Contrariando a tese marxista clássica - ojerizada pelo mecanicismo segundo a qual o cultural (superestrutura) é determinado pelo econômico (infraestrutura), cultura agora engloba todas as práticas de constituição da vida cotidiana ou, nas palavras de Hall (2003, p. 128), torna-se o lócus atravessado "por todas as práticas e constitui a soma do inter-relacionamento das mesmas".

Munidos de um conceito tão amplo de cultura, o foco de estudos dos culturalistas anglo-americanos englobará toda prática produtora de sentido, de poemas de Shakespeare à "literatura de banheiro", de filmes de Bergman a clipes da MTV. O estético, como categoria a partir da qual o trabalho artístico é valorado, passa a ser entendido como elitista e repressivo. Uma forte moralização dá espaço a estudos interdisciplinares em que importa sobretudo as 
táticas de resistência à hegemonia da classe dominante inferidas nos produtos da cultura popular e evidenciadas nas táticas de recepção das produções dos mass media.

Toda prática cultural, a partir de então, é texto; e o instrumental da crítica literária passa a servir para compreender os textos - entenda-se, as práticas culturais produtoras de sentidos - da cultura de massa. Com essa transformação, o texto artístico não é desprezado, mas perde seu lugar privilegiado. Dirá Hall (2003, p. 127) que a arte é "agora definida apenas como uma forma especial do processo social geral: o dar e tomar significados e o lento desenvolvimento dos significados comuns". Nestor García-Canclini (2006, p. 13), representante dos estudos culturais na América Latina, endossará a proposta dos culturalistas de Birmingham, ao afirmar que não se deve "analisar isoladamente as obras de arte ou as obras literárias, mas vê-las na trama complexa de relações de produção cultural".

Produziu-se, com a prática dos estudos culturais, o que Leyla PerroneM oisés (2000) denomina de "minimização da literatura", isto é, o estreitamento do discurso literário, no caso, a uma das formas de cultura, a "sintoma" ou "reflexo" de embates culturais. Esta minimização que resulta dae superação da estética traz como conseqüência a consideração de uma igualdade radical de todos os textos. Ora, quando a estética é reduzida à instância repressiva e deixa de ser um fundamento ou parâmetro a partir do qual se avalia um texto, que diferença existirá entre uma trova de domínio popular, uma pichação de muro e um poema de Drummond? Todos três constituem formas de produção da cultural, meios através dos quais os homens produzem seu fazer cotidiano, se instituem como sujeitos, se colocam diante do poder hegemônico. A este respeito, Beatriz Sarlo (1997, p. 35) comenta:

[...] Deberíamos reconocer abiertamente que la literatura es valiosa no porque todos los textos sean iguales y todos puedan ser culturalmente explicados. Sino, por el contrario, porque son diferentes y resisten una interpretación sociocultural ilimitada. Algo siempre queda cuando explicamos socialmente a los textos literarios y ese algo es crucial. No se trata de una esencia inexpresable, sino de una resistencia, la fuerza de un sentido que permanece y varía a lo largo del tiempo. Para frasearlo de otro modo: los hombres y las mujeres son iguales; los textos no lo son. La igualdad de las personas es un presupuesto necesario (es la base conceptual del liberalismo democrático). La igualdad de los textos equivale a la supresión de las cualidades que hacen que sean valiosos [grifos da autora].

A planificação dos textos, ou a textualização de toda produção cultural, paga, como observa Sarlo, um preço caro: perde-se o traço diferencial que separa um texto de outro, traço este que é o próprio cerne da riqueza dos textos. Poderíamos chamar este diferencial de qualidade estética? Numa época 
do politicamente correto, uma afirmação desta natureza pode ser criticada como elitista, mas se esquece que "qualidade estética" não tem que ver somente com lavor formal, e menos ainda com beletrismo. Um texto esteticamente bem realizado não é sinônimo de um texto bem escrito. Sem dúvida, a crítica de arte e a teoria literária nunca conseguiram chegar ao consenso do que seria qualidade estética, mas isso não é motivo suficiente para considerarmos inútil a tarefa de sondar o valor de um texto para além de seu lugar e sua função na produção da cultura. Há que se questionar, antes de qualquer coisa, se de fato o estético é repressivo e elitista.

A questão é árdua e parece quase ingênuo, ou mesmo maquiavélico, pensar a estética nos parâmetros kantianos de um conhecimento desinteressado. No fundo, trata-se do velho embate entre ética e estética, que Nietzsche e em sua cola a teoria pós-moderna resolvem por uma estetização da ética e que os culturalistas rebatem com a eticização da estética. Os culturalistas são, assim, platônicos às avessas, na medida em que condenam a estética não por seu perigo à pólis, mas por ser um programa de propagação da política hegemônica dominante travestida, através de discurso humanista, de conhecimento desinteressado. Como observa Jameson (1994), remetendo à prioridade ética dos culturalistas, os estudos culturais são antes uma força-tarefa em busca de correção política encampada por diversos grupos sociais, a fim de constituir um "bloco histórico", do que uma teoria com um corpus coeso e coerente.

A queda do estético como fundamento do juízo axiológico traz outra transformação significativa aos estudos literários, qual seja, a passagem da interpretação de textos para o seu uso ou apropriação. Se não há para os culturalistas, como vimos, um centro a partir do qual se possa julgar o texto literário, toda interpretação deve inventar ou escolher este centro; assim, no fundo, toda interpretação é uma apropriação do texto que nunca é desinteressada. Interpretar é fazer política cultural. Cada grupo deve revisitar 0 cânon literário e lê-lo a partir de sua pauta de interesse. Mais que reler o cânon, deve-se corrigir seu evidente eurocentrismo, propondo novas aberturas a autores representantes de minorias étnicas e sexuais.

Beatriz Sarlo (1997) levanta a hipótese de que o cânone dos estudos culturais, mais que se constituir uma superação do eurocentrismo, seja, na verdade, uma adesão à lógica do mercado. 0 desenvolvimento fabuloso da "Madonnologia" ${ }^{3}$ no mundo anglo-americano pode ser uma prova de que Sarlo tem alguma razão. Especialmente nos Estados Unidos, o radicalismo dos estudos culturais freqüentemente é uma atitude de antiintelectualismo conivente

3 Termo cunhado para descrever a profusão de teses, livros e congressos a respeito da pop-star Madonna. 
com o filistinismo da burguesia americana. Jonanthan Culler (1999, p. 57-58), ainda que simpático em muitos pontos com os culturalistas, a este respeito é peremptório:

Quando os estudos culturais denigrem a literatura como sendo elitista, isso é difícil de distinguir de uma longa tradição nacional de filistinismo burguês. Nos Estados Unidos, evitar a alta cultura e estudar a cultura popular não é um gesto politicamente radical ou de resistência tanto quanto tornar acadêmica a cultura de massa.

Emergem aí dois fantasmas que nunca deixaram de mordiscar o calcanhar dos estudos culturais quando das suas abordagens sobre os objetos das culturas popular ou de massa: o "populismo sociológico" e o "miserabilismo", conforme denominações de Armand Mattelart e Érik Neveu (2004). 0 primeiro refere-se à atitude de adesão apaixonada do pesquisador a tudo o que é popular, considerado autêntico, puro e ingênuo em detrimento ao artificialismo e falta de autenticidade dos produtos da alta cultura; no miserabilismo, como um simétrico oposto, o pesquisador continua a olhar os produtos da cultura popular com simpatia, mas o que ressalta então é a pobreza, a rusticidade e a trivialidade daqueles objetos culturais. A primeira abordagem é francamente demagoga; para elogiar uma poesia de cordel não é preciso denegrir a poesia da "alta literatura", considerando que aquela é voz autêntica do povo e esta um artefato artificial. Esta postura, tão freqüente nos estudos culturais, esquece-se de que a cultura popular é em grande parte invenção de etnólogos e folcloristas e não descrições neutras; além disso, produtos da cultura popular freqüentemente veiculam conteúdos mais reacionários que subversivos (o caso do cordel, pródigo em loas a coronéis e ditadores e eivado de racismo e sexismo, serve aqui de exemplo). A abordagem miserabilista, como lembram Mattelart e Neveu (2004, p. 84), oculta "a realidade da institucionalização social de hierarquias culturais freqüentemente interiorizadas pelos dominados". Este fato produz a impressão de inferioridade natural de um cordelista em relação a um poeta da "alta literatura". Cordelistas e pesquisadores miserabilistas, em geral, reproduzem esta impressão inconscientemente.

Porém, o mais grave reducionismo dos estudos culturais, o seu ponto cego é a confiança excessiva, diria dogmática, no paradigma culturalista. Vimos, linhas acima, como este paradigma é insuficiente na abordagem do texto literário. Ao lutarem contra o reducionismo econômico do marxismo tradicional os culturalistas acabaram engendrando um reducionismo cultural. Com isto, afirmam Mattelart e Neveu (2004, p. 87), acabaram "por pensar os bens culturais como vetores puros de mensagens, negligenciando a existência e 0 
funcionamento das indústrias culturais, de um mundo organizado por seus produtos".

Se esta crítica ao paradigma culturalista mover-se para o nível epistemológico surgem outros problemas. Para Terry Eagleton (2005a), o culturalismo é tão reducionista quanto o biologismo, o economicismo e 0 essencialismo. 0 culturalismo é um reducionismo para o qual a dialética entre cultura e natureza deixou de existir, uma vez que a natureza é sempre cultural. Tudo é cultura, dizem; no entanto, para defender seu ponto de vista de que tudo é cultural, o culturalismo tem de recorrer à noção de natureza, que ele nega. Eagleton (2005a, p. 134), explora esta contradição lógica do culturalismo explorando seu ponto cego:

\section{[...] Por que seria tudo redutível à cultura, em vez de a alguma coisa outra coisa? \\ E como estabelecemos essa importante verdade? Por meios culturais, presume- se; mas não seria isso muito parecido com afirmar que tudo se reduz à religião, $\mathrm{e}$ que sabemos disso porque a lei de Deus nos diz assim?}

Eagleton (2005a) também critica, com bastante razão, a concepção caricata de natureza presumida na maior parte dos textos dos culturalistas. Numa época como a nossa, em que a natureza sofre tamanhas transformações, 0 culturalismo continua a vê-la em termos de inércia e imobilidade. Numa época em que a fragilidade da natureza é tão evidente, como falar em naturalizar em termos de tornar inerte e imóvel? Como diz Eagleton (2005, p. 136) com seu característico senso de humor, "é mais fácil extirpar ervas daninhas do que 0 sexismo".

Não restam dúvidas, porém, de que os estudos culturais e todas as manifestações que eles geraram trouxeram, também, ganhos para o processo de reflexão sobre o lugar da literatura. Enumeremos, com o mesmo Eagleton (2005b), três destas conquistas ${ }^{4}$. Em primeiro lugar, os culturalistas nos libertaram "da idéia de que haja uma única maneira correta de interpretar uma obra de arte" (2005b, p. 136). Eagleton quer dizer com isto não que os culturalistas tenham descoberto que a obra literária é plurissignificativa - coisa que já se sabia há muito tempo; o que a teoria cultural menos descobriu que enfatizou foi a íntima vinculação entre interpretação e interesse. Pipocaram, assim, interpretações em que o crítico explora aspectos quiçá imprevistos pelo autor e pela teoria literária tradicional. Estudar, por exemplo, Grande Sertão: Veredas como uma epopéia gay.

Outra conquista, segundo Eagleton, e que continua a empreitada estruturalista, é a idéia, derivada da morte do autor, de que "as obras de arte têm

4 Eagleton (2005b) atribui estas conquistas à teoria cultural de um modo geral, englobando aí também pós-modernos e pós-estruturalistas, e não apenas os estudos culturais. 
uma espécie de 'inconsciente' que não está sob controle de seus produtores" (1995, p. 138). Este ponto acentua o papel de co-criador dado ao leitor, como na estética da recepção, e agudiza nossa percepção "ao jogo de poder e desejo nos artefatos culturais, à variedade de modos como eles podem confirmar ou contestar a autoridade política" (Idem).

Também, mais que nunca, os culturalistas insistiram em apontar e analisar, com um instrumental que deve muito a Foucault, a ligação entre cultura e poder. Ficou mais difícil, a partir de então, sustentar a posição saudosista, derivada de Matthew Arnold, de que a cultura é o refúgio da barbárie, o lugar onde espírito humano dialoga desinteressadamente com as melhores mentes, longe de toda e qualquer mercantilização. Edward Said (1993), com o seu Cultura e imperialismo, deu o golpe de misericórdia nos últimos arnoldianos ao apontar, num trabalho erudito e fartamente documentado, a íntima vinculação entre produções artísticas de várias áreas - óperas, poemas, romances - e consolidação da política imperialista, especialmente a britânica. 0 objetivo de Said não era denunciar os produtos da alta cultura como sendo instrumentos exclusivamente a serviço da dominação européia; pelo contrário, era demonstrar a constituição ambígua da alta cultura, o que lhe dá condições de ser meio de consolidação ou de dominação da política dominante.

Em adendo aos pontos levantados a partir de Eagleton (2005b), outros aspectos positivamente relevantes podem ser atribuídos aos estudos culturais. Vale levantar aqui ao menos um deles: a multiplicação de trabalhados interdisciplinares. Na verdade os estudos culturais, pelo menos tal como configurados pela Escola de Birghman, nunca se propuseram a ser uma disciplina, mas antes um ponto de convergência de várias disciplinas a fim de analisar com mais percuciência os produtos da cultura, sua força de subjetivação e as formas de agências engendradas pelos receptores. Este ecletismo trouxe resultados positivos principalmente nos estudos dos meios de comunicação de massa.

Fica, assim, demonstrado que um balanço dos estudos culturais deve ser cauteloso. Sua atuação foi (e é) ambígua, cheia de avanços e retrocessos. De qualquer maneira, os estudos culturais não usurparam o lugar da teoria literária; eles simplesmente ocuparam uma posição de relevância social que a teoria literária, enredada num linguajar bizantino e em questões muito específicas, já não ocupava ${ }^{5}$. Eagleton (1991), em A função da crítica, ataca esta questão de forma veemente. Para ele, a crítica, quando não virou um ramo das relações

5 Para se ter uma idéia do papel relevante que exerceu a teoria literária basta lembrar, como faz Sarlo (1997), que ela ocupou lugar central na discussão do nacionalismo nos países da América Latina. Basta lembrar, a este respeito, da atuação de Antonio Candido no Brasil e Octávio Paz no México. 
públicas da indústria literária, fechou-se inteiramente em questões que só interessam a seus praticantes. Fazendo uma genealogia da crítica inglesa nos últimos três séculos (XVIII, XIX, XX), dirá Eagleton: "[...] nos primórdios do século XVIII, a crítica dizia respeito à política cultural; no século XIX, sua preocupação era a moralidade pública, e, em nosso século, trata-se de uma questão de "literatura'". Em suma: a crise dos estudos literários é também resultante de um processo histórico interno, e não só da "virada cultural". Apesar disso, haveria meio de sobrevivência deles? Existem questões exclusivas deles a que a teoria cultural não está apta a responder?

\section{CONSIDERAÇÕES FINAIS: A CRISE dOS ESTUdOS LTTERÁRIOS}

Para sobreviver, os estudos literários precisam deixar de bancar o inocente e assumir uma (algumas) especificidade(s) para si. Do contrário, temos que admitir, junto com as vozes conservadoras e nostálgicas, que os estudos culturais "mataram" os estudos literários.

Deixar de bancar o inocente significa repensar o papel ideológico do discurso dos valores estéticos. Sem dúvida, o que os culturalistas não compreendem, com seu gesto de textualizar todo sistema de significação, é que planificar toda produção textual, colocar no mesmo patamar Drummond e letras de rock, é perder uma dimensão primordial da poesia drummoniana, dimensão essa que mesmo sendo definida por termos vagos como "excelência literária" ou "qualidade estética" é o ponto que dá a grandeza ao poeta mineiro. Com isso, não se quer dizer que uma banda de rock deva produzir necessariamente letras inferiores a poemas de Drummond. Não se pode partir de um a priori a partir do qual a "alta literatura" deva sempre ser melhor que as produções das culturas massivas - isto seria uma essencialização equívoca, preconizadora de um preconceito diametralmente oposto àquela do populismo sociológico.

Eis o tropeço da ideologia da "qualidade estética": os valores estéticos nunca determinaram plenamente o cânone. Diversos fatores históricos permitiram que critérios não-estéticos acabassem se equiparando ou mesmo sobrepujando os valores estéticos. No Brasil, três fatores fora da estética exerceram forte pressão na constituição do cânone: a etnia (hegemonia dos autores brancos), o gênero (privilégio aos autores em detrimento das autoras) e a região (a visibilidade bem mais significativa dos escritores de Minas, Rio e São Paulo). Foram estes desequilíbrios da história que levaram diversos grupos a reivindicarem, mais que uma revisão, uma explosão do cânone. Na verdade, o cânone ocidental é muito mais do que uma prescrição do Sr. Harold Bloom, ao contrário do que pensam os radicais. 0 humanista Bloom é muito mais um sábio generoso afogado no mar da informação sem sapiência da cultura pós-moderna que o fantoche do conservantismo elitista, como pensam os inimigos do câno- 
ne. Shakespeare, Dante e Cervantes têm uma história muito longa no processo de "invenção do humano" para dependerem da defesa do autor de 0 cânone ocidental.

O outro desafio dos estudos literários é provarem que têm função específica que não pode ser preenchida pelos estudos culturais. Esta função parece ser: preencher o reducionismo deixado pelos culturalistas, isto é, demonstrar que uma obra literária é sempre algo mais que um produto da e uma intervenção na cultura. Para que isso ocorra é preciso mostrar que o paradigma axiológico dos culturalistas é complementar e não oposto ao paradigma interpretativo. Nesta perspectiva, os estudos culturais e os literários são complementares, e não opositores. Um explora a obra enquanto objeto de cultura; outro dá preferência a questões formais e estéticas. A crítica cultural exige achegas formais, e nisso precisa do instrumental da teoria literária; a crítica literária não pode cair no imanentismo de outrora, e nesse ponto os estudos culturais ensinam como evitar a ingenuidade de considerar uma obra literária como produtora de conhecimentos desinteressados. Para que os estudos literários tenham algum valor social deve-se entender que a independência do estético não significa seu isolamento. Falar da literatura é dar um diagnóstico sobre a cultura.

Não se trata, porém, de propor ingenuamente uma conciliação entre os rebentos de Platão, ainda que às avessas, que propõem um eticização da estética (como nos estudos culturais) e os rebentos de Nietzsche que propõem uma estetização da ética (como na maior parte dos estudos literários).

Ao fim e ao cabo, a situação dos estudos literários é no mínimo complexa: eles têm, ao mesmo tempo, que admitir o caráter nebuloso e ideológico da estética sem, no entanto, abdicar dela. Eles têm que teorizar para resolver estas questões complexas sem, no entanto, transformar esta teorização num isolamento das questões gerais.

Nesta amizade bélica - ou, noutra pauta, nesta guerra amigável - a tendência é dar-se a razão para os estudos culturais, que estão sempre, presumivelmente, do lado do politicamente correto. No entanto, a oposição radical nem sempre está do lado do mais "correto", do mais crítico. Como observa Perrone-Moisés (2000), a abolição de gêneros e hierarquias interessa ao poder, que necessita de produtos transnacionais e de "moda mix". 0 mercado, esta metanarrativa mais poderosa que qualquer relativismo cultural, sabe dar a cada um o seu lugar. Sabe democratizar a crítica aos valores a fim de anulála.

Diluir o texto literário no caldeirão da cultura pode significar não exatamente superar uma tradição elitista chamada estética, mas, simplesmente, 
apagar da literatura sua zona mais inegociável contra o poder hegemônico. Esta é apenas uma hipótese, mas se os estudos literários quiserem sobreviver devem apostar nela.

\section{REFERÊNCIAS}

CONNOR, Steven. Teoria e valor cultural. São Paulo: Loyola, 1994.

CULLER, Jonathan. Teoria literária: uma introdução. São Paulo: Beca, 1999.

EAGLETON, Terry. A função da crítica. São Paulo: M artins Fontes, 1991.

EAGLETON, Terry. A idéia de cultura. São Paulo: UNESP, 2005a.

EAGLETON, Terry. Depois da teoria. Rio de Janeiro: 2005b.

GARCÍA-CANCLINI, Nestor. Estudos sobre cultura: uma alternativa latinoamericana aos cultural studies (entrevista). FAMECOS, Porto Alegre, n. 30, p. 7-15, ago. 2006.

HALL, Stuart. Da diáspora: identidades e mediações culturais. Belo Horizonte: UFM G, 2003.

JAM ESON, Fredric. Sobre os "Estudos de Cultura". In: Novos Estudos, CEBRAP, n. 39, p. 11- 48, jul. 1994.

JAM ESON, Fredric. A cultura do dinheiro: ensaios sobre a globalização. Petrópolis: Vozes, 2001.

JAM ESON, Fredric. Pós-modernismo: a lógica cultural do capitalismo tardio. São Paulo: Ática, 2006.

M ARTTERLART, Armand; NEVEU, Érik. Introdução aos estudos culturais. São Paulo: Parábola, 2004.

PERRONE-M OISÉS, Leyla. Inútil poesia. São Paulo: Cia. das Letras, 2000.

SAID, Edward. Cultura e imperialismo. São Paulo: Cia. das Letras, 1995.

SARLO, Beatriz. Los Estudios Culturales y la crítica literaria en la encrucijada valorativa. Revista de Crítica Cultural, Chile, n. 15, p. 32-38, 1997. 
